\title{
Enhancement of the Anticorrosion Properties of Epoxy Resin Composites through Incorporating Hydroxylated and Silanised Hexagonal Boron Nitride (h-BN)
}

\author{
Jiansan Li ${ }^{*}$, Xiangqi Huang ${ }^{*}$, Jinye Bi
}

School of Mechanical and Automotive Engineering, South China University of Technology, Guangzhou 510640, PR China

*E-mail: jsli@ @scut.edu.cn (J.L.); 201921003345@mail.scut.edu.cn (X.H.)

Received: 13 October 2021 / Accepted: 22 November 2021 / Published: 2 February 2022

Hexagonal boron nitride (h-BN) has the outstanding properties of high-temperature stability, electrical insulation and impermeability against water, oxygen and corrosive ions. However, BN easily agglomerated in the coating, resulting in coating microporous defects and reducing the anticorrosive properties. Thus, h-BN was modified through a two-step treatment, hydroxylation and silanisation. hBN modified by silane coupling agent 3-glycidoxypropyltrimethoxysilane (KH560) was characterized by Fourier transform infrared spectroscopy (FTIR), X-ray photoelectron spectroscopy (XPS) and scanning electron microscopy (SEM). Then, the corrosion resistance of the BN-KH/epoxy resin coatings was measured by electrochemical testing. The results demonstrated that the corrosion current density of the coating with modified h-BN nanosheets was decreased from $2.67 \times 10^{-7} \mathrm{~A} \cdot \mathrm{cm}^{-2}$ to $5.28 \times 10^{-8} \mathrm{~A} \cdot \mathrm{cm}^{-2}$ compared with that of the pure epoxy resin. The impedance of the composite coating with modified hBN is $5.27 \times 10^{7} \Omega \cdot \mathrm{cm}^{2}$, approximately 20 times higher than that of the coating with the original h-BN $\left(1.95 \times 10^{6} \Omega \cdot \mathrm{cm}^{2}\right)$ and the EP coating $\left(4.26 \times 10^{5} \Omega \cdot \mathrm{cm}^{2}\right)$, indicating that BN-KH can protect the coating from damaging corrosive ions and that $\mathrm{BN}-\mathrm{KH} / \mathrm{EP}$ can maintain an excellent anticorrosion property.

Keywords: hexagonal boron nitride; corrosion resistance; modified; electrochemical impedance spectroscopy

\section{$\underline{\text { FULL TEXT }}$}

(C) 2022 The Authors. Published by ESG (www.electrochemsci.org). This article is an open access article distributed under the terms and conditions of the Creative Commons Attribution license (http://creativecommons.org/licenses/by/4.0/). 